Single parts

The prices of single parts are as follows: Vol. A33 D.kr. $115 \quad(\$ 19.00)$ Vol. B33 D.kr. 195 (\$32.00)

\section{Journal of Applied Crystallography}

The following rates will apply for Volume 10 (1977). All subscription rates are fixed in Danish kroner, and the U.S. dollar equivalents given below are subject to exchange-rate fluctuations.

Complete volumes, regular price per volume

D.kr. $425 \quad(\$ 71.00)$

Complete volumes,

reduced price for individuals

D.kr. $210 \quad(\$ 35.00)$

All subscribers in the U.S.A. and Canada should add to the above subscription rates the additional charge for airfreighting as mentioned below.

The same conditions apply to reducedrate subscriptions as in the case of Acta Crystallographica (see below).

Single parts

The price for single parts of Volume 10 (1977) is D.kr. 105 (\$17.00)

\section{Airfreighting of copies to the U.S.A and Canada}

Deliveries of Acta Crystallographica and Journal of Applied Crystallography to the U.S.A. and Canada in 1977 will continue to be air freight to New York and thence by second class mail. The use of this service is obligatory for all subscribers in those countries. The charges in Danish kroner remain the same as in previous years, and are as given below.

\section{Acta Crystallographica \\ Sections A \& B \\ (combined \\ subscription) Add D.kr. $70 \quad(\$ 12.00)$ \\ Section A only Add D.kr. 20 (\$3.50) \\ Section B only Add D.kr.50 (\$ 8.50) \\ Journal of Applied Crystallography$$
\text { Add D.kr. } 20 \quad(\$ 3.50)
$$

Since the charges are fixed in Danish kroner, the U.S. dollar equivalents are subject to exchange-rate fluctuations.
The prices of back numbers have been increased so that they are the same as the subscription rates for the volumes to be published in 1977. The prices of Volumes 1-23 of Acta Crystallographica, which were published before the journal was divided into two sections, have been increased to the same price as the $A$ volumes. The prices are fixed in Danish Kroner and the U.S. dollar equivalents given below are subject to exchange-rate fluctuations.

\section{Prices of back numbers}

Acta Crystallographica

Complete volumes, regular price per volume

Vols. 1-23

D.kr. $465 \quad(\$ 77.00)$

Combined Vols.

24-32

D.kr. $1860 \quad(\$ 310.00)$

Vols. A24-A32 D.kr. 465 (\$77.00)

Vols. B24-B32 D.kr. 1565 (\$261.00)

Complete volumes, reduced price for individuals

Vols. 1-23 D.kr. $195 \quad$ (\$ 32.00)

Combined Vols.$$
\text { 24-32 }
$$

D.kr. 770

$(\$ 128.00)$

Vols. A24-A32

D.kr. 195

Vols. B24-B32

D.kr. 650

$(\$ 108.00)$

\section{Single parts}

The prices of single parts are as follows: Vols. A24-A32 D.kr. 115 (\$19.00) Vols. B24-B32 D.kr. 195 (\$32.00)

Single parts of Volumes $1-23$ are not available.

Journal of Applied Crystallography

Complete volumes, regular price per volume

Vols. $1-9$

D.kr. 425

$(\$ 71.00)$

Complete volumes, reduced prices for individuals

Vols. 1-9

$$
\text { D.kr. } 210
$$

\section{Single parts}

The price of single parts is as follows Vols. 1-9

$$
\text { D.kr. } 105 \quad \text { (\$ 17.00) }
$$

\section{Orders}

Orders of Acta Crystallographica and Journal of Applied Crystallography may be addressed to Munksgaard International Publishers Ltd., 35 Nørre Søgade, DK- 1370 Copenhagen K, Denmark. Orders for complete volumes from subscribers in North America may alternatively be placed through Polycrystal Book Service, P.O. Box 11576, Pittsburgh, Pa. 15238, U.S.A

\section{Index of Crystallographic Supplies}

The Commission on Crystallographic Apparatus of the International Union of Crystallography is preparing a Supplement to the Third Edition (1972) of the Index of Crystallographic Supplies. The Commission would appreciate receiving names and addresses of all manufacturers and suppliers not listed in the 1972 Index. This information should be sent to Professor Reuben Rudman, Department of Chemistry, Adelphi University, Garden City, New York 11530 , U.S.A.

\section{Book Reviews}

Works intended for notice in this column should be sen direct to the Book-Review Editor (J.H. Robertson, Schoo of Chemistry. University of Leeds, Leeds LS2 9JT, England). As far as practicable books will be reviewed in a country different from that of publication.

Количественный рентгенографический фазовый анализ. Ву Л.С. Зевин and Л.Л. Завъялова (Quantitative X-ray phase analysis. By $L$. S. Zevin and $L$. $L$. Zavyalova). Pp. 184, Figs. 53, Tables $26+7$ (in appendices). Moscow: Nedra, 1974. Price $\mathrm{Rb} 0.62$.

This little book is a unique monograph on quantitative $\mathrm{X}$-ray powder analysis. Up to now this has usually been dealt with as one of a number of topics in general handbooks on X-ray methods. The authors have succeeded in collecting a large amount of material spread throughout the literature and presenting it in a comparatively small space. The book is concise, many formulae are given without detailed explanation and the reader is expected to be familiar with the basic principles of $\mathrm{X}$-ray crystallography.

In the first chapter general principles of the method are outlined with a detailed description of problems concerning the superposition of diffraction lines, the application of internal standards and the selection of the proper method of analysis. Chapter 2 deals with the technical details of powder diffractometers manufactured in the USSR and gives some practical instructions on alignment, checking and calibration procedures. New develop- 
ments such as the application of SeemannBohlin geometry, multichannel diffractometry and automatic control are briefly described. The third chapter starts with brief remarks on qualitative powder analysis and proceeds with a description of the steps involved in performing a quantitative analysis, with many practical instructions included. In Chapter 4, different types and sources of error are enumerated and discussed. The authors seem, however, to underestimate the difficulties and errors caused by the strains and imperfections in crystalline materials. The last chapter provides the reader with examples of the quantitative $X$-ray powder analyses of some minerals. The bibliography contains references to 235 papers.

The book may be useful as an introduction to quantitative $X$-ray powder analysis as well as a reference book on the subject.

K. ŁUKASZEWICZ

Institute for Low Temperature

and Structure Research

Plac Katedralny 1

50-950 Wroctaw

Poland

\section{Руководство по рентгеновскому} исследованию минералов. Edited by B.А.Франк-Каменечкий (Handbook for the $\mathrm{X}$-ray investigation of minerals. Edited by V. A. Frank-Kamenetskij). Pp. 400. Leningrad: Nedra. Price $\mathrm{Rb} 1.53$.

This is a fairly complete handbook for a course in the X-ray crystallographic examination of minerals and industrial materials, excluding the analysis of crystal structure (which is discussed only in outline). It includes powder and singlecrystal measurements; qualitative and quantitative phase analysis; photographic and counter methods; high and lowtemperature apparatus; notes on computing, etc. The material is much what might be included in an M.Sc. course in industrial crystallography and indeed the text has been produced by a collective at the Department of Crystallography of the Geological Faculty of Leningrad University for their own use. The account is thorough, if conservative. It hands on many still useful tricks, like using a sliderule with the sliding scales reversed for indexing cubic powder photographs. (It is time that new tricks, based on pocket calculators, were developed for the next generation of crystallographers.) Much of the text is occupied with descriptions of apparatus made in the Soviet Union which is broadly similar to that familiar elsewhere. For identification and indexing powder photographs accuracy in measuring the first few lines is important, so that some account of the Guinier camera would be expected.

Because of its local connexions it is unlikely that this book would circulate far outside the circle of users of Soviet-built apparatus but, today, when the elaborate structure analysis now proceeding in the biological field takes the limelight, it is a useful reminder of where and how many of the bread-and-butter problems are to be tackled.

\section{A. L. MACKAY}

Department of Crystallography

Birkbeck College

Malet Street

London, WC1

England

Surface physics of materials. Vol. II. Edited by J. M. Blakely. Pp. $x i+269$. New York: Academic Press, 1975. U.S. \$27.00.

This is the second volume of a series containing articles by individuals who have made substantial contributions to various problems of topical interest in surface physics. The objectives are to give a broad coverage but with an emphasis upon fundamentals which will remain sound as the subject develops.

The five chapters in this volume contain reviews of Transport of Matter at Surfaces by H. P. Bonzel, Interaction of Atoms and Molecules with surfaces by J. W. Gadzuk, Chemical Analysis of Surfaces by R. L. Park, Surface Vibrations by M. G. Lagally and Interaction between Surfaces: Adhesion and Friction by D. Tabor. As is usual with collections of articles of this type the

Rather than reviewing the various theories of chemisorption Gadzuk concentrates upon the approach in which theoretically exact solutions are obtained to (oversimplified) model problems. The virtue of this approach is that it can give physical insight into the atomistic and electronic mechanisms of chemisorption. This theory is applied to three specific adsorption experiments: $W(100)-H$ : alkali metal adsorption on metals and $5 d$ transition metals on tungsten. The assumptions made about the reader's prior knowledge vary enormously and so the extent to which the objectives will be met is difficult to judge.

Bonzel points out that, in spite of an extensive literature, knowledge of the microscopic processes of surface diffusion is still quite limited. He gives emphasis to the results rather than the experimental techniques and includes references to useful recent reviews. He concludes with a well justified criticism of the use of simple pairwise interaction models.

theory is still under active development.

Park gives a rather philosophical review of the principles of various techniques of surface chemical analysis. The reader wishing to learn how actually to perform an analysis will have to make extensive use of his references.

The atomic vibrations at clean crystalline surfaces are described by Lagally who compares theory and the results obtained using LEED and atomic scattering. Very little data is available on surface phonons and their dispersion and that which exists is difficult to interpret. Lagally's article is a good aid for interpretation.

In an article unusual for this type of book Tabor gives an excellent review of the friction and adhesion between surfaces of 'real' materials as opposed to flat, single-crystal planes. It makes salutory reading for any surface physicist who may have claimed that his work on some carefully selected simple system will throw light upon the mechanisms of adhesion.

In all this is a useful book for a statement of the current position and a useful source of references to original material.

M. PRUTTON

Department of Physics

University of York

York YO1 5DD

England

Crystal growth from high-temperature solutions. By $D$. Elwell and $H$. J. Schell. Pp. vii +634 , Figs. 179, Tables 54. London: Academic Press, 1975. Price $£ 19.80$.

A review of this book by $P$. Hartman has been published in the November issue of Acta Crystallographica, Section A, page 1035. 